УДК $598.2(571.65)$

\title{
НОВЫЙ РАЙОН ГНЕЗДОВАНИЯ ДАЛЬНЕВОСТОЧНОГО КРОНШНЕПА NUMENIUS MADAGASCARIENSIS В ВЕРХОВЬЯХ КОЛЫМЫ
}

\author{
Ю. А. Слепцов \\ ФГБУН Институт биологических проблем Севера ДВО РАН, г. Магадан \\ E-mail: slep-u@yandex.ru
}

\begin{abstract}
В Магаданской области в долине верхнего течения Колымы, в 350 км от известных мест размножения обнаружен новый район гнездования дальневосточного кроншнепа (Numenius madagascariensis). В 2018 г. на сельскохозяйственных угодьях обитало не менее 8 пар птиц. Приведены некоторые данные по гнездовой биологии вида.
\end{abstract}

Ключевые слова: дальневосточный кроншнеп, район гнездования, местообитание.

DOI: 10.34078/1814-0998-2019-2-99-103

\section{ВВЕДЕНИЕ}

Дальневосточный кроншнеп (Numenius madagascariensis Linnaeus, 1766) - редкий вид с сокращающейся численностью. В целях сохранения внесен в Красный список угрожаемых видов МСОП, Красную книгу Российской Федерации (2001), ряд региональных Красных книг, в том числе и в Красную книгу Магаданской области (2008). По последним оценкам, мировая популяция птиц сократилась с 38 тыс. особей (Bamford et al., 2008) до 32 тыс. особей (Bird Life International, 2017). В Магаданской области их число, повидимому, не превышает нескольких сотен размножающихся пар (Красная..., 2008). Гнездовой ареал вида в Восточной Сибири и на Дальнем Востоке очаговый: от бассейна p. Нижняя Тунгуска к востоку до Камчатки, к северу - до центральных районов Якутии, к югу - до Южного Забайкалья, СевероВосточной Монголии и Северо-Восточного Китая. Зимует в Юго-Восточной Азии, Австралии, Новой Зеландии и на о. Тасмания (Нечаев, Гамова, 2009). В Магаданской области гнездовые участки и встречи этого вида связаны преимущественно с побережьем Охотского моря (Andreev, Kondratyev, 2001; Дорогой, 2018) и прилежащими территориями (Кречмар, 2014). Указание на гнездование дальневосточных кроншнепов в горной части бассейна Верхней Колымы (Васьковский, 1966) в настоящее время не нашло подтверждения. Наша наход-

(С) Слепцов Ю. А., 2019 ка гнездовой группировки дальневосточного кроншнепа в долине верхнего течения Колымы расширяет его ареал примерно на 350 км к северу от известных гнездовий на Охотском побережье и подтверждает прежнее предположение о возможном гнездовании птиц в этом районе (Кищинский, 1968).

\section{МАТЕРИАЛ И МЕТОДИКА}

Данные собраны автором в окрестностях пос. Сеймчан $\left(62^{\circ} 04^{\prime} 06^{\prime \prime}\right.$ с. ш., 129 $14^{\prime} 19^{\prime \prime}$ в. д.) в период с 10 мая по 2 августа 2018 г. Пешими и автомобильными маршрутами обследована равнинная местность в долине Колымы площадью около 18 км², представленная обрабатываемыми или зарастающими сенокосными полями и старыми пастбищами с разветвленной сетью дорог (рис. 1).

Границы гнездовых участков птиц определяли визуально по характерному поведению беспокоящихся пар. Поиск гнезд осуществлен методом сплошного обследования некоторых гнездовых участков. Всего найдены 2 гнезда. После обнаружения гнезд измеряли яйца и определяли приблизительное время появления птенцов по их плавучести (Меднис, 1972). В последние 4 дня насиживания до появления птенцов исследователь посещал гнезда с периодичностью 1 раз в сутки. В остальное время птиц старались не беспокоить и наблюдали за ними с большого расстояния при помощи бинокля. Кроме собственных наблюдений, осуществлен сбор опросных данных жителей пос. Сеймчан. 


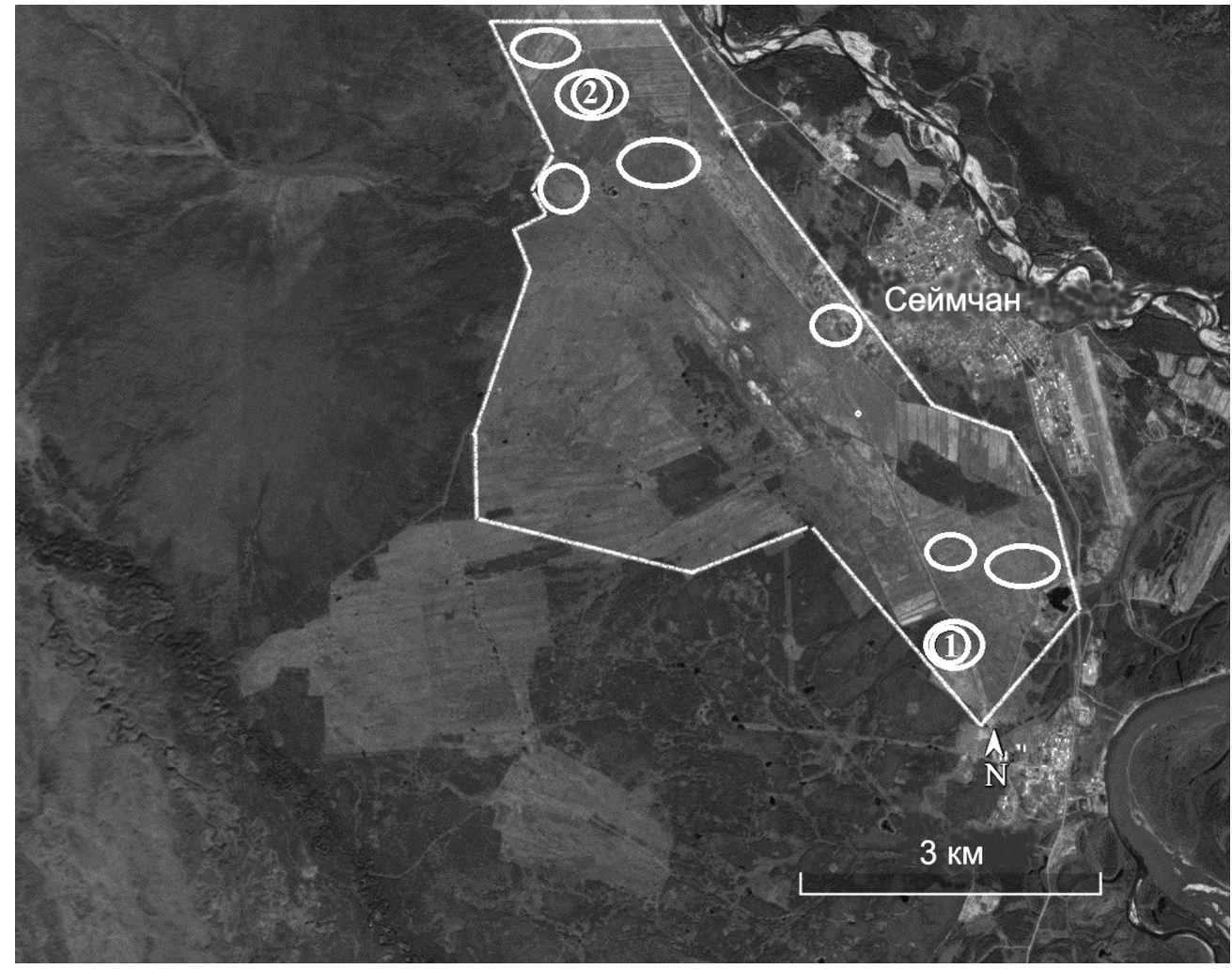

Puc. 1. Размещение на исследованной территории (выделена светлыми линиями) гнездовых участков дальневосточного кроншнепа (светлые окружности) и двух найденных гнезд $(1,2)$

Fig. 1. The location of the Far Eastern Curlew nesting sites (light circles) and two found nests $(1,2)$ on the studied area (light lines)

\section{РЕЗУЛЬТАТЫ}

Прилет птиц на места гнездования отмечен 14 мая. В это время на полях еще оставался снег, что было связано с обилием осадков зимой и с холодной погодой весной. Кроме того, прилет птиц совпал с датой открытия весенней охоты на водоплавающих птиц. По этой причине кроншнепы первое время облетали гнездовые участки на большой высоте (80-100 м). Беспокойство со стороны охотников прекратилось после 23-25 мая.

Первое гнездо было найдено 7 июня в 3 км к югу от пос. Сеймчан на сыром разнотравном лугу, который используется для летнего выпаса крупного рогатого скота (рис. 2, А). Одна из птиц насиживала полную кладку из 4 яиц $(65.5$ $\times 46.5 ; 68.0 \times 46.5 ; 68.8 \times 47.0 ; 67.0 \times 47.0 \mathrm{MM}$, масса яиц составила, соответственно, $68.8,72.7$, 74.8 и 74.2 г). Гнездо располагалось в 10 м от дороги и представляло собой небольшое углубление с платформой из утоптанных сухих листьев злаков и осоки. При последующих посещениях гнезда птица сходила с него на расстояние 60-70 м, при приближении взлетала и сопровождала наблюдателя громкими криками. Это привлекало не только второго партнера, который обычно находился на удалении около 100 м (рис. 3), но и птиц с соседних участков. Од- новременно собирались до 6 кроншнепов. 23 июня одно из яиц в этой кладке оказалось предположительно съеденным хищником. В гнезде оставались остатки скорлупы, которые позже были унесены родителями. 26 июня два яйца имели проклевы, а 27 июня появились 2 птенца массой 45 и 48 г (рис. 4). В одном яйце зародыш погиб, скорее всего, из-за частого беспокойства насиживающих птиц проезжающими по дороге машинами и выпасаемыми на поле коровами. 28 июня выводок покинул гнездо, но держался поблизости от него. Позднее родители увели птенцов от дороги.

Второе гнездо найдено 9 июня в 7 км к северу от первого (см. рис.1). В нем находилась кладка из 4 яиц размерами $70.0 \times 45.2,69.8 \times 43,72 \times$ 46.3 и $69.0 \times 45.0$ мм и массой 73.6, 66.3, 75.6 и 71.0 г (см. рис. 2, Б). Гнездо располагалось на сенокосном поле в 30 м от дороги. Четыре птенца появились 1 июля, 3 июля родители увели их от гнезда. В окрестностях этого гнездового участка беспокоилось до 7 птиц. Покос травы на полях проходит обычно во второй половине июля, поэтому непосредственной опасности уничтожения гнезд уборочной техникой не существует. Степень угрозы выводкам оценить сложно из-за скрытности и активного перемещения птенцов. 

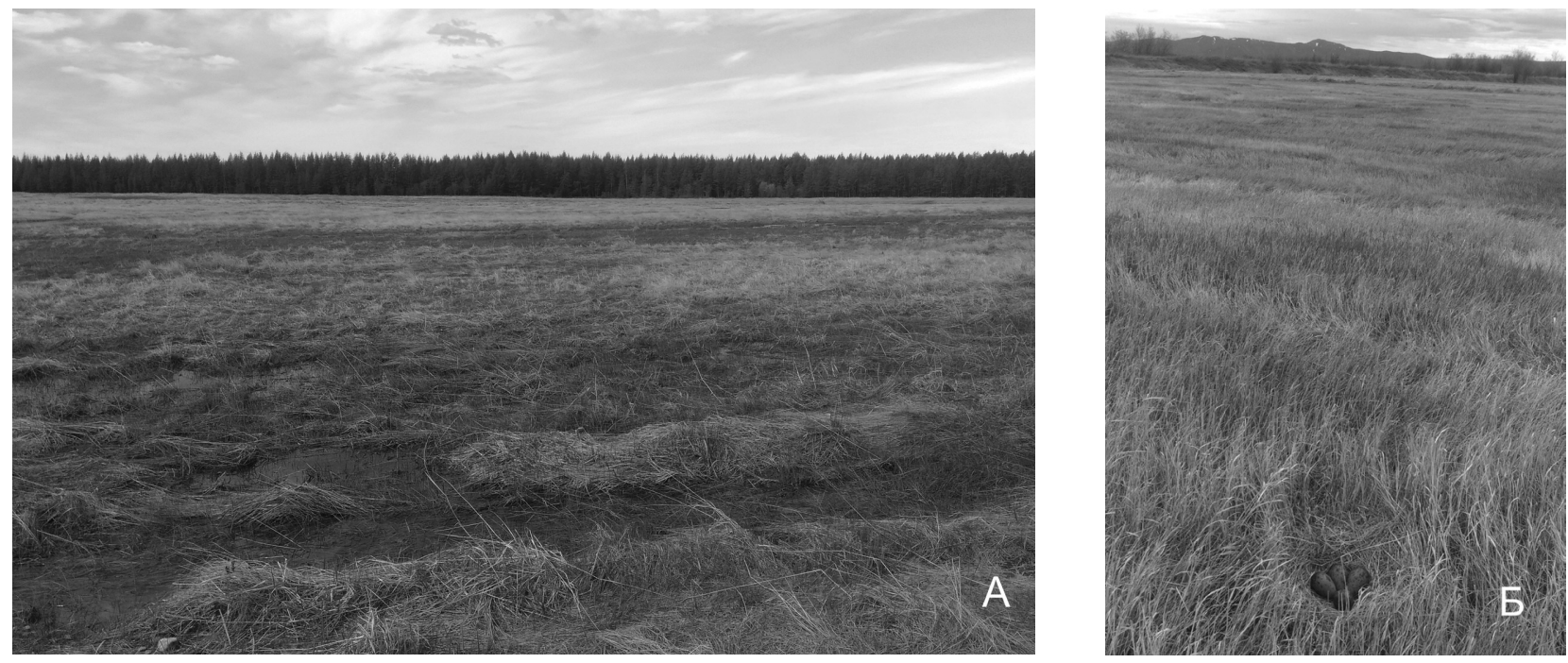

Puc. 2. Места обитания (А) и гнездо (Б) дальневосточного кроншнепа в окрестностях пос. Сеймчан Fig. 2. Habitat (A) and nest (Б) of the Far Eastern Curlew in the vicinities of the settlement of Seymchan

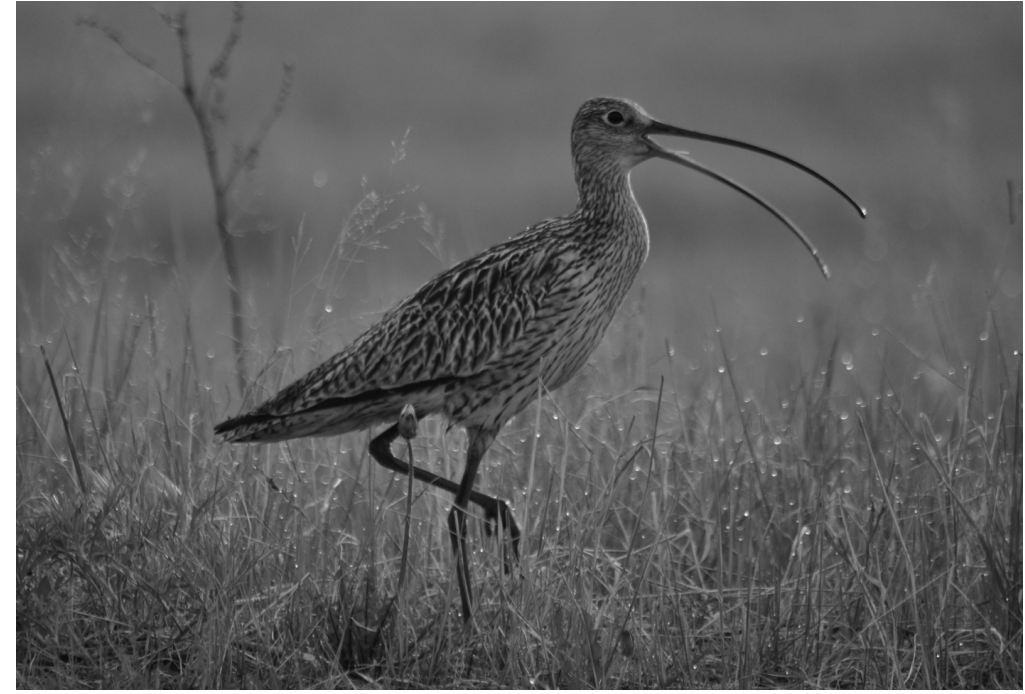

Puc. 3. Дальневосточный кроншнеп на гнездовом участке

Fig. 3. Far Eastern Curlew on the breeding site

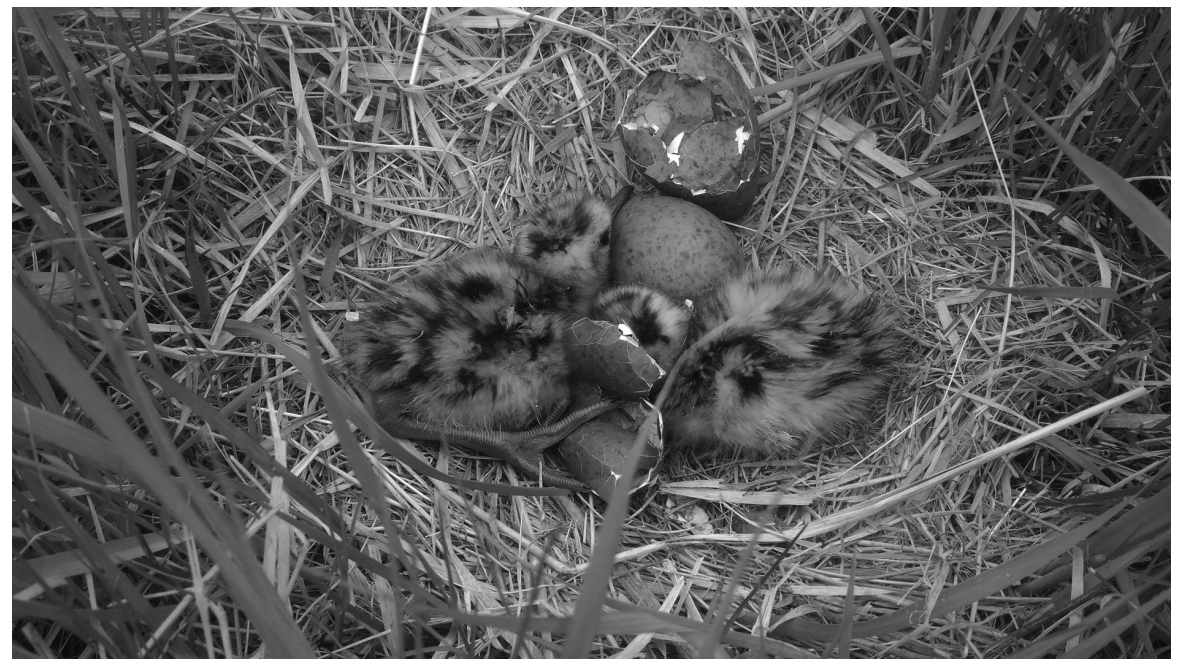

Puc. 4. Гнездо дальневосточного кроншнепа при вылуплении птенцов

Fig. 4. Nest of the Far Eastern Curlew at chicks hatching 
Всего в данной местности в 2018 г. на площа-

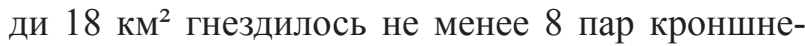
пов. Таким образом, гнездовая плотность составила 0.4 пары/км² (или 1 пара / 2.25 км²). Характерно поселение птиц небольшими группировками из нескольких пар. Так, нами обнаружены локации из 3 и 4 пар, между которыми отмечена отдельная пара. Размещение птиц на обследованной территории связано со степенью увлажнения местности: кроншнепы предпочитали открытые заболоченные разнотравные луговины. Сами гнезда располагались на сухих островках или гривках. Сухие или сильно увлажненные пространства с осоковым кочкарником и кустами в качестве гнездовых участков не использовались. В этих же биотопах до конца мая отмечали и среднего кроншнепа (Numenius phaeopus), но позднее эти птицы держались на более заболоченных участках местности.

В данных условиях несомненную угрозу для кладок дальневосточного кроншнепа и самих птиц представляют лисица (Vulpes vulpes), ворон (Corvus corax), большеклювая ворона (Corvus macrorhuncus), бродячие собаки, а также выпас коров. К основным угрозам относятся незаконная охота во время миграций и сокращение благоприятных для гнездования площадей периодически возникающими пожарами.

\section{ЗАКЛЮЧЕНИЕ И ВЫВОДЫ}

Время заселения данной местности кроншнепами не известно, предположительно, это произошло в начале 2000-х гг., после снижения сельскохозяйственной активности. По опросным данным, птицы гнездятся ежегодно и занимают те же участки. В настоящее время это локальное поселение выглядит стабильным и, как показывают наши наблюдения, достаточно продуктивным. Об этом свидетельствуют фено- логия гнездования, успешность размножения и характер расположения гнездовых поселений птиц на освоенных человеком пространствах. Находка нового района гнездования дальневосточного кроншнепа имеет большое значение в свете охранного статуса птицы и общего сокращения численности.

\section{ЛИТЕРАТУРА}

Васьковский А. П. Список и распространение птиц Крайнего Северо-Востока СССР // Краевед. записки. Магадан, 1966. Вып. 6. С. 84-124.

Дорогой И. В. Авифаунистические находки на юге Магаданской области // Рус. орнитол. журн. 2018. № 1603. C. 2069-2082.

Кищинский А. А. Птицы Колымского нагорья. М. : Наука, 1968. 190 с.

Красная книга Магаданской области. Магадан : 2008. $430 \mathrm{c}$.

Красная книга Российской Федерации. Балашиха Агинское, 2001. 863 с.

Кречмар A. В. Экология и мониторинг птиц приохотской равнинной лесотундры на примере ландшафтов бассейна реки Кава. Владивосток : Дальнаука, 2014. $288 \mathrm{c}$.

Меднис A. A. Определение сроков вылупления утят по плавучести яиц в воде : тез. докл. 8-й Прибалт. конф. Таллин, 1972. С. 64-66.

Нечаев В. А., Гамова Т. В. Птицы Дальнего Востока России (аннот. каталог). Владивосток : Дальнаука, 2009. $564 \mathrm{c}$.

Andreev A. V., Kondratyev A. V. Birds of Koni-Pyagyn and Malkachan Areas // Биологическое разнообразие и экологический статус северного побережья Охотского моря. Владивосток, 2001. Р. 87-122.

Bamford M., Watkins D., Bancroft W. et al. Migratory Shorebirds of the East Asian - Australasian Flyway: Population estimates and internationally important sites. Wetlands International-Oceania, 2008. $300 \mathrm{p}$.

Bird Life International, 2017. Numenius madagascariensis. The IUCN Red List of threatened species 2017. http:// dx.doi.org

\title{
A NEW NESTING AREA OF THE FAR EASTERN CURLEW NUMENIUS MADAGASCARIENSIS IN THE KOLYMA UPPER REACHES
}

\author{
Yu. A. Sleptsov \\ Institute of Biological Problems of the North, FEB RAS, Magadan
}

A new nesting area of the Far Eastern Curlew (Numenius madagascariensis) has been found in Magadan Oblast, in the upper reaches of the Kolyma River, $350 \mathrm{~km}$ from the previously known nesting sites. At least 8 pairs of birds lived in agricultural lands in 2018. Some data on the breeding biology of the species are presented.

Keywords: Far Eastern Curlew, nesting area, habitat. 


\section{REFERENCES}

Andreev, A. V.; Kondratyev, A. V., 2001, Birds of Koni-Pyagyn and Malkachan Areas, Biodiversity and Ecological Status along the Northern Coast of the Sea of Okhotsk, Vladivostok, 87-122.

Bamford, M.; Watkins, D.; Bancroft, W.; Tischler, G.; Wahl, J., 2008, Migratory Shorebirds of the East Asian - Australasian Flyway: Population Estimates and Internationally Important Sites, Wetlands InternationalOceania.

Bird Life International, 2017, Numenius madagascariensis, The IUCN Red List of Threatened Species, http:// dx.doi.org

Dorogoy, I. V., 2018, Avifaunistic Finds in the South of Magadan Oblast, The Russian Journal of Ornithology, 1603, 2069-2082 [In Russian].

Kishchinsky, A. A., 1968, Birds of the Kolyma Highlands, Moscow, Nauka [In Russian].
Krechmar, A. V., 2014, Ecology and Monitoring of Birds from the Priokhotye Plain Forest-Tundra Exemplified by the Kava River Basin Landscapes, Vladivostok, Dalnauka [In Russian].

Mednis, A. A., 1972, Determining Duck Eggs Incubation Stages by Egg Floating in Water, Tallin, 64-66 [In Russian].

Nechaev V. A., Gamova, T. V., 2009, Birds of the Russian Far East (Annotated Catalogue), Vladivostok, Dalnayka, 1-564 [In Russian].

Red Book of Magadan Oblast, 2008, Magadan [In Russian].

Red Book of the Russian Federation, 2001, Balashikha - Aginskoye [In Russian].

Vaskovsky, A.P., 1966, List and Distribution of Birds in the Far North-East of the USSR, Krayevedcheskiye Zapiski, Magadan, Iss. 6, 84-124 [In Russian]. 